\title{
PRESENTACIÓN DE DOS TEXTOS SOBRE JOSEF PIEPER
}

Carlos Mc Cadden*

Los dos artículos que se publican a continuación fueron escritos por Bernard Schumacher y tienen relación con Josef Pieper. El primero es un ensayo biográfico, "Un enamorado de la sabiduría", y el segundo es una entrevista al filósofo, titulada "Reflexiones sobre el fin de la historia y sobre la filosofia".

La idea de llevar a cabo una entrevista surgió cuando Bernard Schumacher se encontraba dándole los últimos retoques a su tesis doctoral titulada: "Una Filosofia de la Esperanza. Ensayo sobre la actualidad filosófica de Josef Pieper." Con ese fin llegamos la tarde del viernes 5 de junio de 1992 a Münster en Westfalia, e inmediatamente asistimos a la clase del ilustre profesor en la Westfälische WilhelmUniversität de Münster, donde Pieper enseña ininterrumpidamente desde 1946, es decir, hace 50 años.

Con cerca de noventa años -J. Pieper nació el 4 de Mayo de 1904el maestro llegó como todos los viernes, sin grandes ceremonias. La clase transcurrió entre las 17 y las 18 horas, pero unos minutos antes de comenzar tuvimos la oportunidad de ver como despachaba asuntos con algunos estudiantes. En la sala-auditorio había alrededor de 300 personas, hombres y mujeres de todas las edades.

* Departamento Académico de Estudios Generales, ITAM. 


\section{CARLOS MC CADDEN}

Puntualmente leyó un documento sobre "La fiesta de la inteligencia" que había preparado para la ocasión y no hubo preguntas al final, aun cuando varias personas lo volvieron a rodear para hacerle consultas.

Después de la clase Bernard Schumacher y yo saludamos a Josef Pieper y la mañana del sábado 6 de junio fuimos a su casa para realizar la entrevista, que duró algo más de tres horas.

Después del matrimonio de sus hijos y la muerte de su esposa, Pieper vive solo y una persona va algunos días a la semana a prepararle sus alimentos y ayudarle con el aseo de la casa.

Mientras Josef Pieper preparaba un café antes de la entrevista, nos hizo algunos comentarios sobre las bondades de su vida casi monacal dedicada a la preparación de sus clases y escritos.

La casa de Pieper se encuentra a unos 20 minutos a pie del centro de Münster, y conserva un bello jardín, por lo que durante la entrevista estuvimos sentados en su oficina-biblioteca con una muy bella vista. El jardín está un poco descuidado, pues era su esposa la que lo cultivaba y desde que ella murió él prefiere dejarlo crecer, sin que por ello haya perdido su belleza.

La entrevista se realizó en el mejor de los ambientes posibles, con una gran atención a las preguntas de su parte y manifestando un vivo interés por contestar con precisión.

En la tarde del sábado nos invitó a visitar a una amiga escultora, por lo que, muy oportunamente, la plática giró en torno a la belleza.

La razón del retraso en la publicación de esta entrevista se debe a que el mismo Josef Pieper quiso revisar y releer el texto varias veces para darle su forma actual.

Entretanto la tesis doctoral de Bernard Schumacher, que fue dirigida por el Prof. Evandro Agazzi, ya ha sido defendida en la Universidad de Friburgo, Suiza, y obtuvo el premio Vigener. Actualmente está siendo traducida para su publicación en español. 